\title{
Health consequences for mother and baby of substantial pre-conception weight loss in obese women: study protocol for a randomized controlled trial
}

\author{
Sarah Price ${ }^{1}$, Alison Nankervis ${ }^{2,5}$, Michael Permezel ${ }^{3}$, Luke Prendergast ${ }^{4}$, Priya Sumithran ${ }^{1}$
} and Joseph Proietto ${ }^{*}$

\begin{abstract}
Background: Current guidelines for the management of obesity in women planning pregnancy suggest lifestyle modification before conception. However, there is little evidence that lifestyle modification alters pregnancy outcomes. Bariatric surgery results in significant weight loss. This appears to reduce the risk of adverse pregnancy outcomes for the mother but may increase the risk of adverse outcomes for the infant. In order to reduce the risks of obesity-related adverse pregnancy outcomes for both mother and offspring, alternative approaches to the management of obesity in women planning pregnancy are needed.

Methods/design: This study, a two-arm, parallel group, randomized control trial, will be conducted at the Metabolic Disorders Centre, University of Melbourne. This trial will recruit 164 women aged 18-38 years with a body mass index of 30-55 kg/m² who plan to conceive in the next 6-12 months. Women will be randomized to one of two 12-week interventions (Group A and Group B). Group A will aim for modest weight loss (MWL; $\leq 3 \%$ body weight) using a hypocaloric diet. Group B will aim for substantial weight loss (SWL; 10-15\% body weight) using a modified very low energy diet (VLED) program. All participants will be asked to comply with National Health and Medical Research Council (NHMRC) guidelines for exercise and will be provided with standard pre-pregnancy advice according to Royal Australian and New Zealand College of Obstetrics and Gynaecology guidelines. All participants will then be observed for the subsequent 12 months. If pregnancy occurs within the 12-month follow-up period, data on weight and metabolic status of the mother, and pregnancy outcomes of mother and offspring will be recorded.

The primary outcome is maternal fasting plasma glucose at 26-28 weeks' gestation, given that this is known to correlate with pregnancy outcomes. Time to conception, live birth rate, gestational weight gain, and a composite of adverse pregnancy outcomes for mother and baby will comprise the secondary outcomes.
\end{abstract}

Discussion: There is increasing emphasis on obese women losing weight before conception. To date, no randomized controlled trial has demonstrated an effective means of weight loss that results in improved pregnancy outcomes for both mother and baby. This study intends to determine if substantial pre-conception weight loss, achieved using a VLED, improves pregnancy outcomes for mother and baby when compared with standard care. This research will potentially change clinical care of an obese woman planning pregnancy.

Trial registration: ANZCTR, 12,614,001,160,628. Registered on 5 November 2014.

Keywords: Pregnancy, Pre-conception, Obesity, Weight loss, Glucose metabolism, Pregnancy outcomes, Randomized trial

\footnotetext{
* Correspondence: j.proietto@unimelb.edu.au

${ }^{1}$ Department of Medicine, University of Melbourne, Heidelberg Repatriation

Hospital, Waterdale Rd., Heidelberg, VIC 3081, Australia

Full list of author information is available at the end of the article
}

(c) The Author(s). 2018 Open Access This article is distributed under the terms of the Creative Commons Attribution 4.0 International License (http://creativecommons.org/licenses/by/4.0/), which permits unrestricted use, distribution, and reproduction in any medium, provided you give appropriate credit to the original author(s) and the source, provide a link to the Creative Commons license, and indicate if changes were made. The Creative Commons Public Domain Dedication waiver (http://creativecommons.org/publicdomain/zero/1.0/) applies to the data made available in this article, unless otherwise stated. 


\section{Background}

Obesity is present in one in three women of childbearing age [1]. Currently, guidelines for the management of obesity in women planning pregnancy are based on consensus view and lack supporting evidence. It is critically important that we have evidence-based weight loss tools that reduce the risk of obesity-related pregnancy outcomes for both mother and fetus. This study aims to determine if substantial weight loss achieved using a modified very low energy diet (VLED) program fulfils this clinical need.

The impact of maternal obesity on pregnancy outcomes have been well described. Maternal risks include gestational diabetes, gestational hypertension and preeclampsia, medically indicated induction of labor, instrumental delivery, and primary Cesarean section [1]. Fetal risks include large-for-gestational age (LGA), pre-term delivery, hyperbilirubinemia, hypoglycemia, and need for admission to the special care nursery or intensive care unit $[1,2]$. Maternal obesity also increases the risk of congenital anomalies $[3,4]$ and perinatal death $[5,6]$.

Pre-gravid maternal obesity [7], maternal gestational diabetes (GDM) [7], and being born LGA [8] are the most significant risk factors for obesity in childhood. Obesity in childhood is the strongest predictor of obesity in adulthood [9]. Emerging evidence suggests the metabolic status of the mother may "program" the offspring's long-term risk of metabolic disease [10-12].

To date, studies aimed at reducing obesity-related adverse pregnancy outcomes have focused on limiting gestational weight gain. More than 50 such interventional trials have been conducted but these studies have, at best, been only very modestly effective in reducing adverse pregnancy outcomes. The LIMIT study was a large, well-designed study of lifestyle modification during pregnancy. The study demonstrated no risk reduction for delivering a baby $\geq 90$ th centile for gestational age and no improvement in maternal pregnancy or birth outcomes. There was also no statistically significant difference in gestational weight gain between the control and intervention groups [13]. Similarly, the UPBEAT trial showed that a program of diet and exercise had no impact on the risk of gestational diabetes and LGA offspring in obese pregnant women [14]. These important studies inform us that alternative approaches to the management of obesity in women planning pregnancy are needed.

A review of five national guidelines from Canada, Ireland, the United Kingdom, Australia/ New Zealand, and the United States of America showed that there are significant differences in the management of obese women planning pregnancy between countries [15]. All guidelines included in the review recommend weight loss before pregnancy using lifestyle modification such as diet and exercise. These recommendations are made on the basis of consensus opinion. The United Kingdom guidelines offer specific advice on how to monitor weight and change health behavior, including the recommendation to reach a body mass index (BMI) of $18.5-24.9 \mathrm{~kg} / \mathrm{m}^{2}$ before conception [15]. However, for a woman of average height $(165 \mathrm{~cm})$ and a BMI of $40 \mathrm{~kg} / \mathrm{m}^{2}$, a $42-\mathrm{kg}$ weight loss would be required to reach BMI $24.9 \mathrm{~kg} / \mathrm{m}^{2}$. Lifestyle modification in the Counterweight Programme $(n=642)$ demonstrated a mean weight loss of $3.0 \mathrm{~kg}$ after 12 months [16]. Similarly, a lifestyle program in obese infertile women $(n=236)$ demonstrated a mean weight loss of $4.4 \pm 5.8 \mathrm{~kg}$ over six months [17]. While modest weight loss has metabolic benefits for the woman [18-20], there is no evidence that it reduces the risk of obesityrelated pregnancy complications.

Numerous retrospective studies of bariatric surgery before conception have demonstrated a reduction in adverse pregnancy outcomes for the mother [21-25]. The largest study $(n=627)$ demonstrated that bariatric surgery (mean weight loss from surgery to early pregnancy $=37 \mathrm{~kg}$ [BMI $43.7 \mathrm{~kg} / \mathrm{m}^{2}$ to $\left.30.3 \mathrm{~kg} / \mathrm{m}^{2}\right]$ ) was associated with a reduction in maternal gestational diabetes and LGA infants. However, risk of small-forgestational-age (SGA) infants and possibly perinatal mortality was increased [26]. In this study, the median interval from surgery to conception was 12 months, suggesting that even after conception, rapid surgeryinduced weight loss was occurring. Catalano has shown that those women who gain inadequate weight during pregnancy $(<5 \mathrm{~kg})$ have a significantly increased risk of SGA infants [27]. SGA infants are at similar long-term risk of metabolic disease to LGA infants [27].

There is limited experience with the use of medications such as sibutramine, phentermine, and orlistat as an adjunct to lifestyle modification in the pre-pregnancy setting $[28,29]$. In these studies, slightly more weight loss was achieved when the medication was used. However, live birth rate was not substantially improved. There are no published studies examining the impact of GLP-1 analogs in the pre-pregnancy setting. However, case studies of inadvertent use of GLP-1 analogs in the pre-pregnancy and early pregnancy setting do exist and no adverse outcomes are reported [30]. This is an area of future potential research [31,32].

VLEDs result in $10-15 \%$ weight loss over 12 weeks in an adult population [33]. Such programs may be particularly suitable for pre-conception weight loss as they promote rapid weight loss which assists program engagement [34], induce sufficient weight loss to improve fertility $[35,36]$, ensure adequate intake of protein which is associated with favorable pregnancy outcomes if pregnancy occurs [37], and can be stopped before conception, ensuring gestational weight gain is not affected. Some have argued that VLEDs should not be used in 
women planning pregnancy due to the potential of exposing the developing fetus to ketosis. This concern has been based on animal studies, which show potential harm to the pup when exposed to high-level ketosis for the entire period of gestation and lactation [38]. Women on VLED programs are advised to use contraception. Hence, the early developing fetus would only be exposed to ketosis if unintended pregnancy occurred. Reassuringly, the human fetus is regularly exposed to brief periods of ketosis in the context of hyperemesis gravidarum [39], type 1 diabetes [40], and normal pregnancy [41]. In all such cases, there is no evidence of harm to the fetus. Multiple small studies of VLED pre-pregnancy support this concept $[42,43]$.

The primary metabolic abnormalities associated with obesity are insulin resistance and hyperinsulinemia [44]. Insulin resistance not only affects glucose metabolism; increased free fatty acids and triglycerides are hallmarks of insulin resistance. The obese woman begins pregnancy with greater insulin resistance than her normal weight counterpart. There is a further $50-60 \%$ increase in insulin resistance due to the pregnancy itself [45]. This progressively increases as the pregnancy progresses [46]. If the beta cell cannot compensate for the increase in insulin resistance, glucose levels rise. The developing fetoplacental unit is exposed to these metabolic changes [47].

The seminal Hyperglycaemia and Adverse Pregnancy Outcome (HAPO) study $(n=23,316)$ demonstrated that even within the "normoglycemic" range, small increases in maternal glucose are associated with adverse pregnancy outcomes [48]. Similarly, a small decrease in maternal glucose is associated with a lower risk of adverse pregnancy outcomes. For example, a reduction in maternal fasting glucose from glucose category $5(5.0-5.2 \mathrm{mmol} / \mathrm{L})$ to glucose category $3(4.5-4.7 \mathrm{mmol} / \mathrm{L})$ (a $10 \%$ reduction in fasting glucose) will result in a reduction in the rate of neonates born LGA from $16.5 \%$ to $10.1 \%$, cord blood C-peptide from $17.7 \%$ to $8.2 \%$, and the rate of primary Cesarean section from $23.7 \%$ to $18.5 \%$ [48].

The HAPO data were re-analyzed to investigate the impact of BMI on adverse pregnancy outcomes [49]. This study demonstrated that both maternal hyperglycemia and obesity at 24-32 weeks' gestation are independently associated with adverse pregnancy outcomes. However, the combination has a greater impact than either one alone. The same association exists if prepregnancy BMI (based on patient recall) is considered. Weight loss improves glycemic control $[19,20]$. Prepregnancy weight reduction has the potential to improve pregnancy outcomes, directly through weight loss and indirectly through improved glycemic control.

Regardless of the method of weight loss, the counterregulatory responses to weight loss will result in a tendency to weight regain [50]. While any weight regain is not ideal, multiple studies suggest that weight maintenance for 12 months is possible [51, 52]. Importantly, the rate of weight regain is not altered by the rate of weight loss [34]. This would allow a window for conception at a time of lower weight.

In considering weight loss in an obese woman before pregnancy, we must identify a weight loss target that both increases fertility and decreases the risks of adverse pregnancy outcomes due to obesity. This study aims to address this need by exploring the impact of substantial pre-conception weight loss in obese woman on maternal and fetal pregnancy outcomes.

\section{Aim}

Primary aim: To determine if non-surgical substantial pre-conception weight loss (10-15\% body weight) in obese (BMI $\geq 30 \mathrm{~kg} / \mathrm{m}^{2}$ ) women causes $\mathrm{a} \geq 10 \%$ reduction in fasting glucose at $26-28$ weeks' gestation when compared with modest pre-conception weight loss ( $\leq 3 \%$ body weight loss).

\section{Secondary aims:}

The secondary aims of the study are to determine if, in obese women (BMI $\left.\geq 30 \mathrm{~kg} / \mathrm{m}^{2}\right)$, non-surgical substantial pre-conception weight loss (10-15\% body weight) when compared with modest pre-conception weight loss $(\leq 3 \%$ body weight), results in:

1. A reduction in the composite end point of maternal gestational diabetes (IADPSG definition), LGA, intrauterine growth restriction (IUGR), gestational hypertension/pre-eclampsia, delivery before 37 weeks' gestation, primary Cesarean section, shoulder dystocia/birth injury, neonatal hypoglycemia, neonatal

hyperbilirubinemia, neonatal special care nursery, or intensive care admission.

2. A reduction in the rate of maternal gestational diabetes (IADPSG definition).

3. A reduction in the rate of LGA infants.

4. A reduction in the rate of IUGR.

5. A reduction in the rate of gestational hypertension/ pre-eclampsia.

6. A reduction in the rate of delivery before 37 weeks' gestation.

7. A reduction in the rate of primary Cesarean section.

8. A reduction in the rate of birth injury/shoulder dystocia.

9. A reduction in the rate of neonatal hypoglycemia.

10. A reduction in the rate of neonatal hyperbilirubinemia.

11. A reduction in that rate of neonatal special care nursery or intensive care admission.

12. A reduction in maternal and neonatal length of stay.

13. A decrease in the time to conception. 
14. An increase in live birth rate.

15. No difference in maternal gestational weight gain.

\section{Methods/design}

A two-arm, parallel group, randomized control trial will be conducted in the Metabolic Disorders Centre, University of Melbourne. Obese (BMI $30-55 \mathrm{~kg} / \mathrm{m}^{2}$ ) women planning pregnancy in the next 6-12 months will be recruited using social media advertisements $\left(\right.$ Facebook $^{\circ}$ ) and via referral from a Weight Control Clinic at a tertiary hospital.

Subjects who identify themselves as potential trial candidates will click on the Facebook $^{\odot}$ advertisement and will be directed to a secure study website. An online 'Registration of Interest' form will be completed. This will be received by the study co-ordinator and will trigger a phone screening to ensure that the subject is (a) planning pregnancy in the next 6-12 months (b) lives in reasonable proximity to study sites (c) meets the BMI criteria. Potential trial participants will be sent a participant information and consent form. If they wish to proceed, they will contact the study co-ordinator and a screening appointment will be booked.

At the screening visit, patients will be reviewed by a medical doctor. After signing the consent form, medical history and current medications will be recorded. A medical summary will also be sought from the local doctor. A physical examination will be performed including height, weight, waist circumference and blood pressure. Patients unsuitable for the study will be referred to a weight management clinic in a tertiary hospital.

Inclusion criteria are women who meet the following:

- BMI $30-55 \mathrm{~kg} / \mathrm{m}^{2}$

- 18-38 years of age

- Planning pregnancy in the next 6-12 months

- Willing to undergo a weight loss program and to avoid pregnancy during this program (16 weeks).

- Living in Victoria, Australia.

Exclusion criteria are:

- $\mathrm{BMI}<30$ and $>55 \mathrm{~kg} / \mathrm{m}^{2}$

- Age $<18$ and $>38$ years old

- Current pregnancy/lactation

- Significant medical or psychiatric illness that would preclude the use of a VLED for 12 weeks

- Current use of drugs/complementary medicines known to impact weight

- Diabetes (Type 1 Diabetes or Type 2 Diabetes)

- Diabetes therapies (except Metformin). Metformin use in the context of Polycystic Ovarian Syndrome (PCOS) is not an exclusion. However, participants will be asked to with-hold the dose on the day before all study blood tests. Participants are not permitted to up-titrate the dose of Metformin for the duration of the study. The dose may be ceased if medically indicated.

- Discretion of the investigator

Withdrawal criteria are:

- The participant wishes to discontinue

- The participant is unwilling or unable to comply with the study protocol.

- The participant misses more than one trial visit during the weight loss phase of the study.

- The participant is pregnant before the completion of the weight maintenance phase. In this case, the pregnancy will be followed but data will not be included in study results.

- The participant is withdrawn at the discretion of the investigator for a medical, psychological or social reason.

\section{Randomization}

Women will be randomized to the two treatment arms (Group A and Group B) using randomly permuted blocks of size 2, 4 or 6 (also randomly chosen) within 6 strata accounting for BMI (30-34.9; and 35-50 kg/m²), age (18-29 and $30-38$ year-old), and parity (0 or $1+$ ).

\section{Group A: Moderate Weight Loss (MWL)}

Nutritional advice will be delivered by a qualified dietician in accordance with the 'Australian Guide to Healthy Eating'. Daily energy expenditure will be calculated based on Basal Metabolic Rate and Activity Level (Harris-Benedict formula). A hypocaloric diet $(500 \mathrm{cal}$ deficit from the daily energy expenditure) will be recommended to achieve a weight loss of $0.5 \mathrm{~kg}$ per week. A food diary and an 'Allan Borushek's Calorie, Fat and Carbohydrate Counter' book (Hinkler books, 2014) will be provided to participants as tools to assist weight loss. Over 12 weeks, $\leq 3 \%$ of body weight loss is expected. This is current best practice.

\section{Group B: Substantial Weight Loss (SWL)}

Women will be instructed to replace two meals per day with a commercially available very low energy dietary formulation, Optifast ${ }^{\bullet}$ (Nestle Nutrition, Australia). The third meal of the day must consist of $150 \mathrm{~g}$ of protein (meat, chicken, fish, tofu, eggs), 2 cups of low-starch vegetables and salad dressed with 2 tablespoons of oil (to stimulate the gallbladder and prevent gallstones). Nutritional advice will be delivered by a qualified dietician. The group will receive 'Allan Borushek's Calorie, Fat and Carbohydrate Counter' book (Hinkler books, 2014) but will be advised that the information in this 
book will only be relevant after completion of the intervention phase. Total daily calorie intake is approximately 800 cal. Over 12 weeks, $10-15 \%$ total body weight loss is expected [33] (Table 1).

\section{Intervention}

The trial will involve three phases.

\section{Phase 1: Weight loss (Weeks 0-12)}

Weeks 0 \& 12 (all participants) On arrival to the clinic, a fasting blood sample $(20 \mathrm{ml})$ will be taken for measurement of plasma glucose, insulin, lipid profile (total cholesterol, LDL, HDL, triglycerides, nonesterified fatty acids (NEFA)), leptin and C-reactive protein (CRP)). The specified period of fasting is $8-12 \mathrm{~h}$ with blood samples drawn between 08:00 and 10:00 am. A urine and serum pregnancy test will be performed. Urinalysis will be performed for urinary ketones. Maternal anthropometry (weight, waist and hip circumference, skin fold thickness measurement) and blood pressure will be measured (see Data and Biosample collection 1.1 and 1.2).

Participants will be asked to avoid pregnancy using a medically proven form of contraception. Adequate methods of contraception include barrier contraceptives, hormonal contraceptives (oral, implanted, injectable) or mechanical products (intra-uterine device). The patient's understanding of this will be documented. Standard prepregnancy medical advice for obese women planning pregnancy will be discussed. This includes the use of a multi-vitamin containing iodine $150 \mu \mathrm{g}$ (one tablet PO daily) and high dose folate (5 mg PO daily) [53].

The medical doctor will discuss the national guidelines for exercise with the participant using the NHMRC brochure titled "Australia's Physical Activity and Sedentary Behaviour Guidelines for Adults". Participants will be provided with a pedometer (Yamax 200S) and will be asked to wear the pedometer for 7 consecutive days (Week 2 of the weight loss phase). An average step count will be recorded. Exercise does not play a significant role in short-term weight loss but we wish to demonstrate that differences in weight loss between the groups are not due to exercise $[54,55]$.

Participants will be provided with a survey to take home and complete before the next study visit. This survey is based on the previously published Health in Pre-conception, Pregnancy and Post-birth (HIPPP) Study [56]. It is intended to assess areas including depression, anxiety, body image and activity level, which may impact health during pregnancy. This is expected to take around $1 \mathrm{~h}$ to complete. The decision to participate or not participate in this aspect of the study will not impact involvement in other aspects of the study.
Weeks 2,4,6,8,10 Maternal anthropometry and blood pressure will be measured (see Data and Biosample collection 1.1 and 1.2). A brief medical history will be taken and medication will be adjusted as required. A urine test will be collected. A urine pregnancy test and urinalysis for urinary ketones will be performed. The dietician will provide ongoing dietary counselling.

\section{Phase 2: Weight maintenance (Weeks 13-16)}

Both study arms will be asked to adopt a healthy balanced diet based on the "Australian Guide to Healthy Eating" for a period of 4 weeks and will be asked to aim for weight maintenance. At week 16, maternal anthropometry and blood pressure will be measured (see Data and Biosample collection 1.1 and 1.2). If greater than $3 \mathrm{~kg}$ of weight regain has occurred, participants will see the dietician for further dietary counselling. At the end of this phase, women will be advised contraception can be ceased and they may try to conceive.

\section{Phase 3a: Pre-pregnancy (Week 17-60)}

Women from both groups will be seen every 3 months whilst attempting to conceive. Maternal anthropometry and blood pressure will be recorded (see Data and Biosample collection 1.1 and 1.2). Any medical issues and changes in medication will be documented. A urine pregnancy test will be performed. Women will see the dietician to assist weight maintenance. If pregnancy has not occurred within 12 months of Phase 1 of the trial, involvement in the trial will cease. If appropriate, the women will be referred on for fertility care.

\section{Phase 3b: Pregnancy (Conception-3 days post delivery)}

Women will contact the study coordinator when a home pregnancy test is positive. There is no limitation to how pregnancy is achieved (spontaneous pregnancy, clomiphene induction, artificial reproductive technology). Method of conception and approximate estimated date of conception will be recorded. It is accepted that date of conception may initially be difficult to determine. Subsequent study booking will be based on a derived date when late menstrual period dates, BHCG titre and/ or ultrasound results are known. This is what would occur in standard clinical practice. Likely obstetric care provider will be recorded. Medical records including the results of the standard $75 \mathrm{~g}$ Oral Glucose Tolerance Test (26-28 weeks' gestation), all ultrasonography reports and the Victorian Maternity Record will be obtained in all women.

If women elect to attend The Mercy Hospital and Royal Women's Hospital for obstetric care, they will be asked to agree to an additional four study visits throughout pregnancy. 
Table 1 Sample constituents of the VLED product

\begin{tabular}{|c|c|c|c|}
\hline \multicolumn{4}{|c|}{ 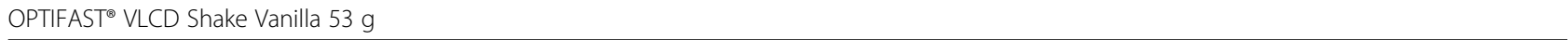 } \\
\hline $\begin{array}{l}\text { Servings per pack: } 12 \\
\text { Serving Size: } 53 \mathrm{~g} \text { (Powder) }\end{array}$ & Average quantity per serving & Average quantity per $100 \mathrm{~g}$ & Ave quantity per $100 \mathrm{~mL}$ (made up with $200 \mathrm{~mL}$ water) \\
\hline \multirow[t]{2}{*}{ Energy } & $840 \mathrm{~kJ}$ & $1580 \mathrm{~kJ}$ & $354 \mathrm{~kJ}$ \\
\hline & $201 \mathrm{Cal}$ & 379 Cal & $85 \mathrm{Cal}$ \\
\hline Protein & $20 \mathrm{~g}$ & $37.7 \mathrm{~g}$ & $8.4 \mathrm{~g}$ \\
\hline Fat-total & $4.5 \mathrm{~g}$ & $8.5 \mathrm{~g}$ & $1.9 \mathrm{~g}$ \\
\hline - Saturated & $0.9 \mathrm{~g}$ & $1.7 \mathrm{~g}$ & $0.4 \mathrm{~g}$ \\
\hline - Linolenic acid & $1.2 \mathrm{mg}$ & $2.2 \mathrm{mg}$ & $0.5 \mathrm{mg}$ \\
\hline - a-Linolenic acid & 196 mg & 370 mg & $83 \mathrm{mg}$ \\
\hline Carbohydrate & $18.2 \mathrm{~g}$ & $34.4 \mathrm{~g}$ & $7.7 \mathrm{~g}$ \\
\hline - Sugars & $10.1 \mathrm{~g}$ & $19 \mathrm{~g}$ & $4.3 \mathrm{~g}$ \\
\hline - Lactose & $9.5 \mathrm{~g}$ & $18 \mathrm{~g}$ & $4.0 \mathrm{~g}$ \\
\hline Dietary fiber & $3.6 \mathrm{~g}$ & $6.8 \mathrm{~g}$ & $1.5 \mathrm{~g}$ \\
\hline Sodium & $215 \mathrm{mg}$ & 410 mg & $92 \mathrm{mg}$ \\
\hline Vitamin A & $345 \mu \mathrm{gRE}$ & $650 \mu \mathrm{gRE}$ & $146 \mu \mathrm{gRE}$ \\
\hline Thiamin (B1) & $0.58 \mathrm{mg}$ & 1.10 mg & $0.2 \mathrm{mg}$ \\
\hline Riboflavin (B2) & $0.74 \mathrm{mg}$ & $1.40 \mathrm{mg}$ & $0.3 \mathrm{mg}$ \\
\hline Niacin & 8.0 mgNE & 15 mgNE & 3.4mgNE \\
\hline Pantothenic acid & $2.7 \mathrm{mg}$ & $5 \mathrm{mg}$ & $1.1 \mathrm{mg}$ \\
\hline Vitamin B6 & $1.0 \mathrm{mg}$ & $1.9 \mathrm{mg}$ & $0.4 \mathrm{mg}$ \\
\hline Biotin & $10.6 \mu \mathrm{g}$ & $20 \mu \mathrm{g}$ & $4.5 \mu \mathrm{g}$ \\
\hline Folic acid & $110 \mu \mathrm{g}$ & $210 \mu \mathrm{g}$ & $47 \mu \mathrm{g}$ \\
\hline Vitamin B12 & $1.1 \mu \mathrm{g}$ & $2 \mu \mathrm{g}$ & $0.4 \mu \mathrm{g}$ \\
\hline Vitamin C & $40 \mathrm{mg}$ & 76 mg & $17 \mathrm{mg}$ \\
\hline Vitamin D & $3.7 \mu \mathrm{g}$ & $7 \mu \mathrm{g}$ & $1.6 \mu \mathrm{g}$ \\
\hline Vitamin E & 7.4 mgTE & 14 mgTE & $3.1 \mathrm{mgTE}$ \\
\hline Vitamin K & $31.8 \mu \mathrm{g}$ & $60 \mu \mathrm{g}$ & $13.4 \mu \mathrm{g}$ \\
\hline Calcium & $420 \mathrm{mg}$ & 800 mg & 180 mg \\
\hline Chromium & $13 \mu g$ & $25 \mu \mathrm{g}$ & $5.6 \mu \mathrm{g}$ \\
\hline Copper & $1.1 \mathrm{mg}$ & $2 \mathrm{mg}$ & $0.4 \mathrm{mg}$ \\
\hline Fluoride & $340 \mu \mathrm{g}$ & $650 \mu \mathrm{g}$ & $146 \mu \mathrm{g}$ \\
\hline lodine & $98 \mu g$ & $185 \mu \mathrm{g}$ & $42 \mu \mathrm{g}$ \\
\hline Iron & $8.0 \mathrm{mg}$ & $15 \mathrm{mg}$ & $3.4 \mathrm{mg}$ \\
\hline Magnesium & 160 mg & 300 mg & $67 \mathrm{mg}$ \\
\hline Manganese & $0.8 \mathrm{mg}$ & $1.5 \mathrm{mg}$ & $0.3 \mathrm{mg}$ \\
\hline Molybdenum & $18.6 \mu \mathrm{g}$ & $35 \mu \mathrm{g}$ & $7.8 \mu \mathrm{g}$ \\
\hline Phosphorus & $360 \mathrm{mg}$ & $680 \mathrm{mg}$ & 150 mg \\
\hline Selenium & $40 \mu \mathrm{g}$ & $75 \mu \mathrm{g}$ & $16.8 \mu \mathrm{g}$ \\
\hline Zinc & $4.2 \mathrm{mg}$ & $8 \mathrm{mg}$ & $1.8 \mathrm{mg}$ \\
\hline Potassium & 955 mg & $1800 \mathrm{mg}$ & 405 mg \\
\hline Chloride & 280 mg & $530 \mathrm{mg}$ & 120 mg \\
\hline Gluten & Nil detected & Nil detected & Nil detected \\
\hline
\end{tabular}


- Visit 3.1 (12 weeks pregnant): Maternal anthropometry and blood pressure will be measured (see Data and Biosample collection 1.1 and 1.2). A fasting maternal blood sample $(20 \mathrm{ml})$ will be taken for measurement of plasma glucose, insulin, lipid profile (total cholesterol, LDL, HDL, triglycerides, non-esterified fatty acids (NEFA), leptin and C reactive protein (CRP).

- Visit 3.2 (26-28 weeks pregnant): Maternal weight, skin fold thickness measurements and blood pressure will be taken. Maternal bloods will be repeated as for Visit 3.1. A kit for maternal and cord blood collection (containing tubes and instructions) will be given to participants. This will be packed into the baby bag of subjects. This method of cord blood collection has been used successfully in the past.

- Visit 3.3 (Delivery): After the 3rd stage of labour, cord blood $(20 \mathrm{ml})$ will be taken from the umbilical vein using direct puncture of the vessel with needle and syringe. Maternal blood will be taken (see Data and Biosample collection 1.1 and 1.2).

- Visit 3.4 (24-72 h post-delivery): Fetal anthropometry (see Data and Biosample collection 1.3) will be performed by one of two trained persons based on the protocol used in the HAPO study [57]. Maternal anthropometry and blood pressure will be performed (see Data and Biosample collection 1.1 and 1.2). Gestational weight gain will be calculated (to the nearest $0.1 \mathrm{~kg}$ ).

All standard pregnancy care, including the decision to proceed with an early $75 \mathrm{~g}$ Oral Glucose Tolerance Test (OGTT), will occur at the discretion of the treating maternity team. If gestational diabetes is diagnosed at any gestation, treatment should proceed per usual local guidelines. The diagnosis of gestational diabetes will be documented in the participant file and all medical therapy used to manage gestational diabetes will be recorded. Given that these women will not have an OGTT at 26-28 weeks' gestation, glucose samples from these participants cannot be used in the analysis of the primary outcome. Study samples should otherwise be collected per the study protocol (Fig. 1).

\section{Outcome measures}

The results of the standard $75 \mathrm{~g}$ oral glucose tolerance test (OGTT) performed at 26-28 weeks' gestation will be collected in all participants (except those who had an early OGTT which was positive; these subjects will not have a OGTT at 26-28 weeks' gestation and therefore these subjects are excluded from the primary outcome). The fasting maternal plasma glucose from the $75 \mathrm{~g}$ Oral Glucose Tolerance Test performed at 26-28 weeks' gestation will be used for analysis of the primary outcome.
This test is part of standard maternity care and the sample could be taken in any one of the pathology collection centres across Victoria. Storage and processing of samples will occur according to the standard protocol of the pathology company. While it is acknowledged that samples may be processed in different laboratories using different techniques (hexokinase method or glucose oxidase method), it is anticipated that using this sample as the primary outcome will maximise the number of samples available for analysis. If samples are taken, stored and processed according to the standard protocol of the pathology company, the inter-assay variation is likely to be extremely low [58].

All women who agree to take part in the study throughout pregnancy will also have fasting glucose samples taken at their scheduled $26-28$ weeks' gestation study visit. This glucose sample will not be taken on the same day as the $75 \mathrm{~g}$ OGTT but will be taken during the same $26-28$ week gestation window. This sample will be taken after an 8-12 h fast and between 08:00 and 10:00 am. Samples will be stored and batch tested as per Methodology 1.4. Analysis of these glucose samples will occur by the hexokinase method. These results will be compared to the fasting maternal plasma glucose samples from the $75 \mathrm{~g}$ Oral Glucose Tolerance Test. These samples will be used to validate the glucose results that comprise the primary outcome.

After delivery, the Victorian Maternity record will be obtained in all women who become pregnant. This will provide data on secondary outcomes including large-for gestational age, pre-eclampsia, small for gestational age (SGA), delivery before 37 weeks' gestation, caesarean section, shoulder dystocia/birth injury, neonatal hypoglycemia, neonatal hyperbilirubinemia, and special care nursery or neonatal intensive care admission.

\section{Data and biosample collection}

Study data will be collected by trained research staff. All blood samples will be taken from the right or left cubital fossa, after an 8-12 h fast, between 08:00-10:00 am. Dietary advice will be provided by appropriately trained dieticians. Personal information will be maintained separately from data, and is accessible only by study coordinators and principal investigators.

\subsection{Maternal anthropometry}

Body weight will be measured (to the nearest $0.1 \mathrm{~kg}$ ) using calibrated digital scales. Waist and hip circumferences will be measured (to the nearest $0.1 \mathrm{~cm}$ ) using a standard tape measure according to the WHO guidelines (at the end of a normal expiration, at the midpoint between the lower margin of the last palpable rib and the top of the iliac crest, and around the widest portion of the buttocks, as the average of two measurements). Skin fold thickness measurement will occur according to 


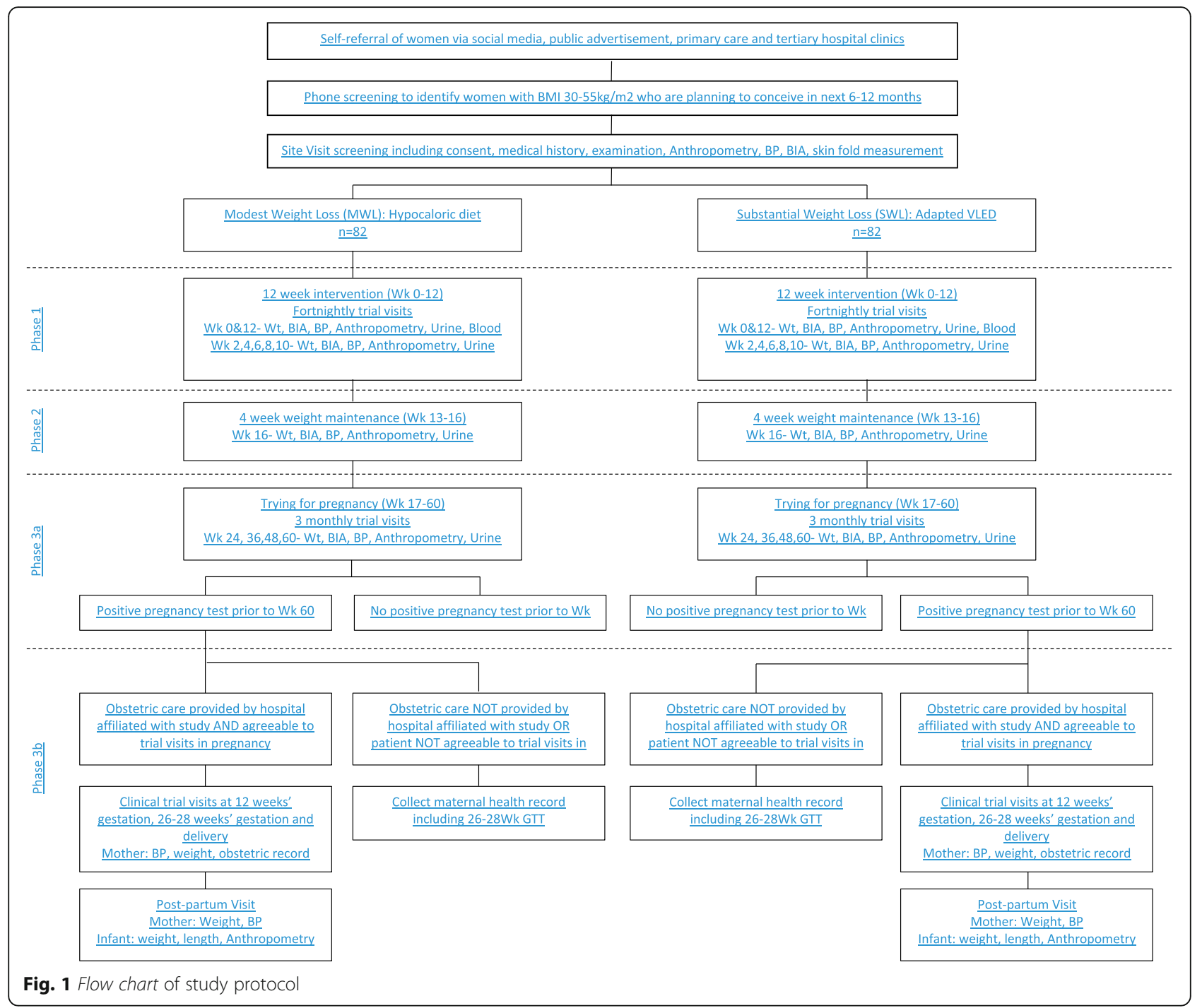

the protocol published by Kannieappan and will involve triceps, biceps, subscapular skinfold thickness measurements plus arm circumference [59]. Measurements will be taken fortnightly during the weight loss phase (weeks $0-12$ ), at week 16 and then 3 monthly for 12 months or until conception occurs. Post-conception measurements will occur at 12 and 26 weeks' gestation and within $72 \mathrm{~h}$ of delivery.

\subsection{Maternal blood pressure}

Blood pressure will be measured from the left arm, with an automated sphygmomanometer after participants have been seated for $5 \mathrm{~min}$. All measurements will be taken with a large cuff.

\subsection{Fetal anthropometry}

Weight will be measured (within $24 \mathrm{~h}$ of delivery) on digital calibrated scales. Length will be measured using a measuring board, and head circumference measured using a tape measure. Harpenden calipers will be used to measure skinfold thickness. in the mid-axillary line, triceps fold and subscapular fold. All measurements will be taken on the left side and repeated until a consistent, stable reading is obtained. Neonatal body fat estimation will be performed using the formula derived by Catalano [60]. There is no significant difference between this anthropometric estimate of body fat and total body electric conductivity.

\subsection{Laboratory assays}

At each visit requiring a blood sample, 3 serum tubes, 1 lithium heparin tube and 1 fluoride EDTA tube with be taken. Samples will be mixed by inversion and centrifuged at 4 degrees Celsius. Plasma from the three serum tubes will be aliquoted into 5 microtubes for insulin/c-peptide, $\mathrm{CRP} /$ lipids and leptin with two spare samples. Plasma from the lithium heparin tube will aliquoted into 2 microtubes for free fatty acids. Plasma from the fluoride ETDA 
with be aliquoted into two microtubes for glucose. Plasma samples will be batched for analysis to minimise interassay error. Sample will be stored at -80 degrees Celsius before analysis. Spare tubes will only be used in the event of a processing error. Our laboratory (Austin Pathology, Melbourne, Australia) has experience in measuring glucose, insulin, lipids, C-peptide, C-reactive protein (CRP), free fatty acids and leptin. The study database allows management of the samples. All analysis will be carried out on anonymised samples (Fig. 2).

\section{Study management and governance}

This two-arm, parallel group, randomized control trial is led by investigators based at the University of
Melbourne. This is an academic institution comprising investigators from Melbourne Health, Austin Health, Royal Women's Hospital, and Mercy Health. All involved institutions are based in Melbourne, Australia. The principal investigators will be responsible for all decisions in regard to management and delivery of the study. Data collected will be re-identifiable (coded) so that it remains confidential but could be identifiable if critical results are noted. All study information is treated as confidential and is securely stored. Data monitoring, protocol modifications, and reporting of serious adverse events will occur according to the specification of research ethics committees. All principal investigators will have access to the interim dataset and

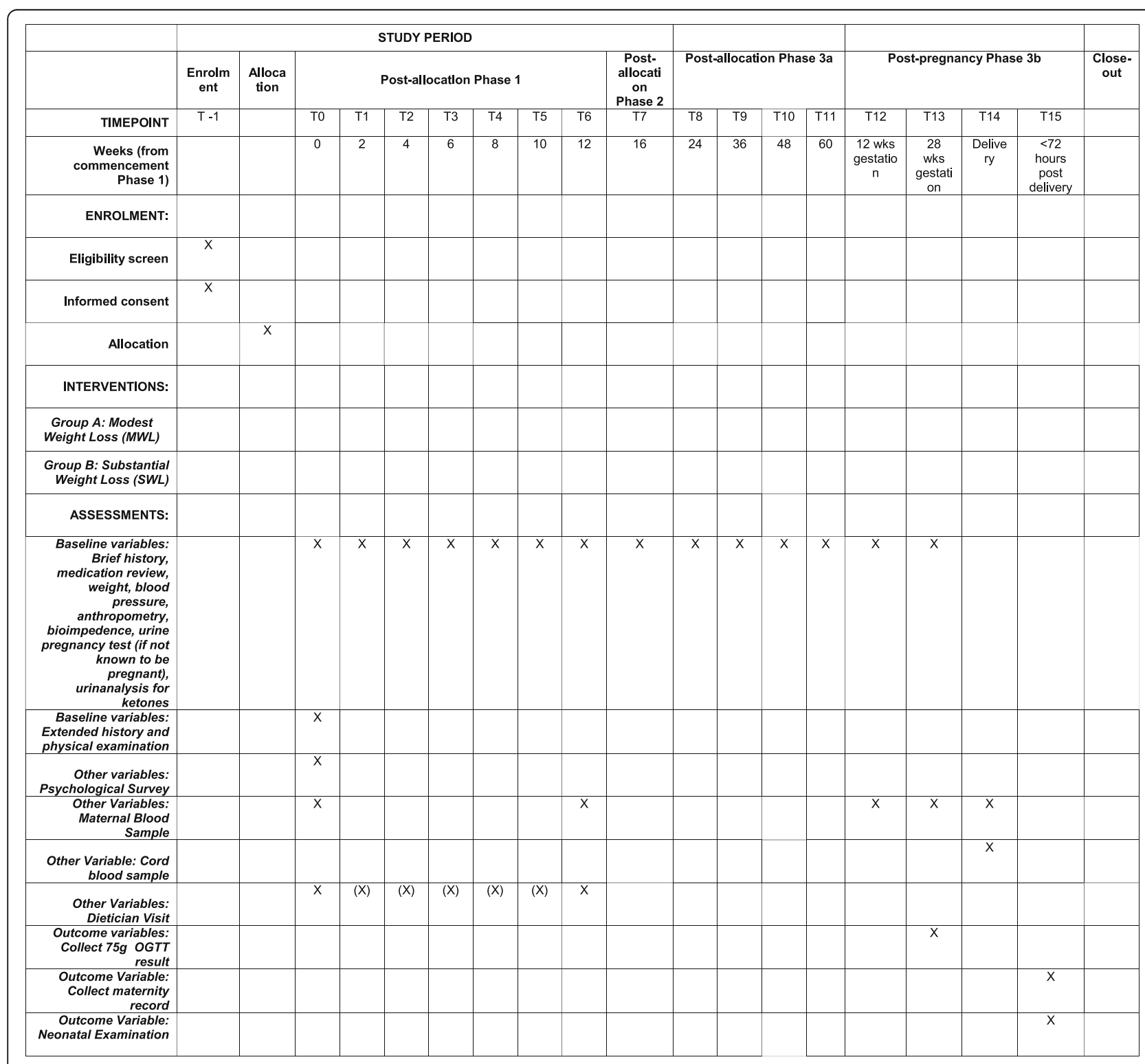

Fig. 2 Example of template of recommended content for the schedule of enrolment, interventions, and assessments. $X$ denotes tasks which must be completed in all study participants. $(X)$ denotes tasks that are recommended but are not required 
any decision to terminate the trial will be made by consensus. Principal investigators will be responsible for communication of the final results study results via publication in peer-reviewed journals.

\section{Statistical analysis/Power calculation}

Most studies investigating the impact of maternal weight on pregnancy outcome have used the incidence of LGA neonates as the primary outcome. If this study used the same outcome, $>2000$ women would be required to have sufficient offspring to achieve adequate power. This is clearly not practical. The HAPO data demonstrated a strong and continuous association between maternal fasting glucose at 24-32 weeks and pregnancy outcomes, including LGA neonates. Therefore, change in maternal fasting glucose at $26-28$ weeks' gestation can be used as a proxy for the incidence of LGA neonates.

In our pilot study, Phase 1 of the study demonstrated substantial weight loss (SWL) resulted in a reduction in maternal fasting glucose of approximately $10 \%$ (actual 9. $12 \%, \mathrm{SE}=1.83, n=24)$ compared to the modest weight loss (MWL) group $(1.24 \%, \mathrm{SE}=1.40, n=14)$. This is similar to previous studies by Sumithran [50] and Purcell [34]. In phase 3 of the pilot study $(n=10$, MWL 3 , SWL 7 ), glucose reductions were maintained at both 12 weeks' gestation and 26-28 weeks' gestation in both groups. Allowing for at least a moderate effect size of 0.6 for difference in percentage decrease in glucose at 26-28 weeks' gestation (i.e. difference in means $=6$, $\mathrm{SD}=10$; or slightly larger difference in means and larger SD) we require 45 women in each group to achieve $80 \%$ power.

We anticipate $45 \%$ of participants will not achieve a live birth within the study time-frame. This would include 20\% drop-out during the weight loss phase. The anticipated drop-out rate is based on pilot data, on previous studies conducted by Purcell [34] and Rothberg [61], and by the lifestyle interventional study conducted by Mutsaerts [17]. We anticipate a further $25 \%$ of participants will fail to become pregnant within 12 months or will experience an early pregnancy loss at < 20 weeks' gestation. This is based on the data from Kort et al. who found women with a mean BMI of $36 \mathrm{~kg} / \mathrm{m}^{2}$ had a conception rate of $88 \%$ or $54 \%$ when losing $\geq 10 \%$ weight or $<10 \%$ weight, respectively [28]. We therefore require approximately 164 individuals.

The primary outcome will only consider those women who conceive and have a $75 \mathrm{~g}$ Oral Glucose Tolerance Test at 26-28 weeks' gestation. Where appropriate, secondary outcomes will be analyzed both considering only those women conceive and also by intention to treat.

\section{Discussion}

Obesity is reaching epidemic proportions among women of reproductive age [1]. The cost of hospitalization during pregnancy for a woman with a BMI $>26 \mathrm{~kg} / \mathrm{m}^{2}$ is five times greater than for a woman of normal weight (BMI $\left.18-25 \mathrm{~kg} / \mathrm{m}^{2}\right)[55,62]$. However, hospitalization costs explain only a limited proportion of the total financial costs on the healthcare system. As maternal BMI increases, practical difficulties in providing every aspect of obstetric care increase, such as more antenatal visits, more intensive maternal and fetal monitoring, increased induction of labor, and increased risk of operative delivery requiring bariatric trolleys and operating theatre tables $[62,63]$. This amounts to huge healthcare expenditure.

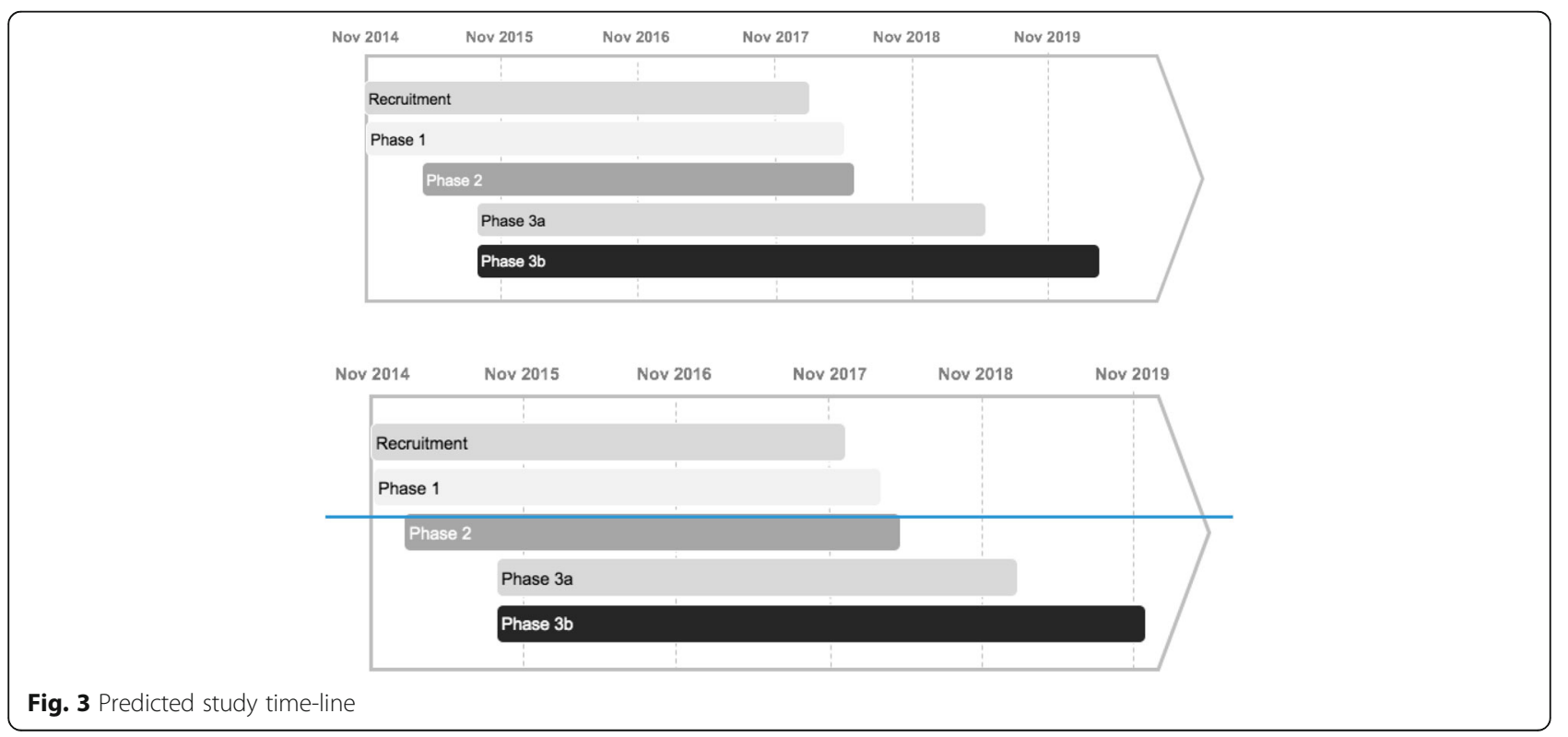


The maternal and neonatal risks of obesity in pregnancy are well documented. There is also growing evidence that obesity during pregnancy is a significant driver of obesity in the next generation [64, 65]. The rising rates of obesity in children and young people, and the financial implications of this trend, have been captured in both prominent scientific publications and the lay press over the past five years. Despite this, we still have no safe and effective tool for weight management in obese women planning pregnancy.

Studies aimed at limiting gestational weight gain typically recruit participants at $12-20$ weeks of pregnancy. The metabolic state of the mother in early pregnancy $(<12$ weeks' gestation) programs early placental function and plays a critical role in the metabolic status of the mother in late pregnancy [66]. On this basis, the intervention will occur after the critically important early phase of pregnancy. In order to give women sufficient time to achieve the metabolic benefits of weight loss and for the early pregnancy to be exposed to this metabolic environment, it is clear that weight loss must occur before conception.

VLEDs may be a particularly suitable weight loss tool for the pre-conception period given the potential to induce rapid, substantial weight loss before conception while ensuring adequate maternal protein and micronutrient intake. Given a VLED program can be stopped before conception, fetal growth is unlikely to be compromised. The fertility benefit of VLED-induced weight loss has already been demonstrated [29, 35, 42, 67]. However, it is uncertain if VLED-induced weight loss reduces the incidence of obesity-related adverse pregnancy outcomes.

This study aims to determine whether substantial prepregnancy weight loss, achieved using a VLED program, can cause a clinically significant reduction in maternal glucose at 26-28 weeks' gestation when compared with standard care. The HAPO study demonstrated a strong and continuous association between fasting plasma glucose at 24-32 weeks' gestation and adverse pregnancy outcomes including LGA neonates [48]. It is impractical to use incidence of LGA neonates as a primary outcome in a study such as this, given the large sample size that would be required. Therefore, this study uses the known association between maternal glucose and pregnancy outcomes to inform us about the impact of the intervention. Other impacts of non-surgical substantial preconception weight loss will also be explored including time to conception, gestational weight gain, live birth rate, and the incidence of individual adverse pregnancy outcomes including gestational diabetes, LGA neonates, and SGA neonates.

Should this study demonstrate that non-surgical substantial preconception weight loss achieved using a
VLED program is safe, effective, and reduces the incidence of obesity-related adverse pregnancy outcomes, this evidence has the potential to change pre-conception guidelines in obese women planning pregnancy. The use of VLED to achieve substantial weight loss in obese women before pregnancy offers the possibility of reducing the healthcare costs associated with antenatal care while improving maternal and fetal outcomes (Additional file 1).

\section{Trial status}

Recruitment began on 5 November 2014. Recruitment will be completed by 15 February 2018. The last participant will complete Phase 1 in May 2018, Phase 2 in June 2018, and Phase 3a in June 2019. Assuming the last participant became pregnant on the last day of Phase 3a, Phase 3b would be completed by March 2020 (See Fig. 3).

\section{Additional file}

Additional file 1: SPIRIT 2013 checklist: Recommended items to address in a clinical trial protocol and related documents. (DOC $122 \mathrm{~kb}$ )

\section{Abbreviations}

BIA: Bioelectrical impedance analysis; BP: Blood pressure; GDM: Gestational diabetes; IUGR: Intrauterine growth restriction; LGA: Large for gestational age; SGA: Small for gestational age; VLED: Very low energy diet

\section{Acknowledgements}

Basic scientists from the Murdoch Children's Research Institute and Austin Health provided advice on aspects of the study design.

\section{Funding}

The study is funded by the University of Melbourne and competitive funding obtained from the Norman Beischer Medical Research Foundation. SP is supported by a NHMRC post-graduate scholarship.

\section{Authors' contributions}

SP, JP, AN, MP, and PS were involved in development of the study protocol. LP performed the statistical analysis. SP prepared the initial draft of the manuscript. All authors read, contributed to editing, and approved the final manuscript.

\section{Ethics approval and consent to participate}

The study has ethics approval from the Human Research Ethics Committee ( $\mathrm{HREC} / 14 / \mathrm{MH} / 71)$ and from the Human Ethics Committee of Mercy Health (R14/19). Consent to participate is sought after full explanation from the study doctor. Written consent is documented by signing the approved Participant Information and Consent Form

\section{Competing interests}

The authors declare that they have no competing interests.

\section{Publisher's Note}

Springer Nature remains neutral with regard to jurisdictional claims in published maps and institutional affiliations.

\section{Author details}

${ }^{1}$ Department of Medicine, University of Melbourne, Heidelberg Repatriation Hospital, Waterdale Rd., Heidelberg, VIC 3081, Australia. 'Diabetes Service, University of Melbourne, Royal Women's Hospital, Flemington Rd., Parkville, VIC 3050, Australia. ${ }^{3}$ Department of Obstetrics and Gynaecology, University of Melbourne, Mercy Hospital for Women, Studley Rd.,, Heidelberg, VIC 3050, Australia. ${ }^{4}$ Department of Mathematics and Statistics, LaTrobe University, 
Kingsbury Drive, Bundoora, VIC 3081, Australia. ${ }^{5}$ Department of Medicine, University of Melbourne, Royal Melbourne Hospital, Grattan St., Parkville, VIC 3083, Australia.

Received: 18 May 2017 Accepted: 28 March 2018 Published online: 24 April 2018

\section{References}

1. Callaway LK, Prins JB, Chang AM, Mclntyre HD. The prevalence and impact of overweight and obesity in an Australian obstetric population. Med J Aust. 2006;184:56-9.

2. Ramachenderan J, Bradford J, McLean M. Maternal obesity and pregnancy complications: a review. Aust N Z J Obstet Gynaecol. 2008:48:228-35.

3. Rasmussen SA, Chu SY, Kim SY, Schmid CH, Lau J. Maternal obesity and risk of neural tube defects: a metaanalysis. Am J Obstet Gynecol. 2008; 198.611-9.

4. Persson M, Cnattingius S, Villamor E, Söderling J, Pasternak B, Stephansson $\mathrm{O}$, et al. Risk of major congenital malformations in relation to maternal overweight and obesity severity: cohort study of 1.2 million singletons. BMJ. 2017;357:j2563.

5. Aune D, Saugstad OD, Henriksen T, Tonstad S. Maternal body mass index and the risk of fetal death, stillbirth, and infant death: a systematic review and meta-analysis. JAMA. 2014;311:1536-46.

6. Cnattingius S, Bergström R, Lipworth L, Kramer MS. Prepregnancy weight and the risk of adverse pregnancy outcomes. N Engl J Med. 1998:338:147-52.

7. Catalano PM, Farrell K, Thomas A, Huston-Presley L, Mencin P, de Mouzon $\mathrm{SH}$, et al. Perinatal risk factors for childhood obesity and metabolic dysregulation. Am J Clin Nutr. 2009;90:1303-13.

8. Boney CM, Verma A, Tucker R, Vohr BR. Metabolic syndrome in childhood: association with birth weight, maternal obesity, and gestational diabetes mellitus. Pediatrics. 2005;115:e290-6.

9. Whitaker RC. Predicting preschooler obesity at birth: the role of maternal obesity in early pregnancy. Pediatrics. 2004;114:e29-36.

10. Barker DJ. The developmental origins of insulin resistance. Horm Res. 2005 64(Suppl 3):2-7

11. Barker DJ. The origins of the developmental origins theory. J Intern Med. 2007;261:412-7

12. Yajnik CS. Transmission of obesity-adiposity and related disorders from the mother to the baby. Ann Nutr Metab. 2014;64(Suppl 1):8-17.

13. Dodd JM, Turnbull D, McPhee AJ, Deussen AR, Grivell RM, Yelland LN, et al. Antenatal lifestyle advice for women who are overweight or obese: LIMIT randomised trial. BMJ. 2014;348:g1285.

14. Briley AL, Barr S, Badger S, Bell R, Croker H, Godfrey KM, et al. A complex intervention to improve pregnancy outcome in obese women; the UPBEAT randomised controlled trial. BMC Pregnancy Childbirth. 2014;14:74

15. Kominiarek MA, Chauhan SP. Obesity before, during, and after pregnancy: a review and comparison of five national guidelines. Am J Perinatol. 2016;33:433-41.

16. Counterweight Project Team, McQuigg M, Brown JE, Broom Jl, Laws RA Reckless JP, et al. Engaging patients, clinicians and health funders in weight management: the Counterweight Programme. Fam Pract. 2008; 25(Suppl 1):i79-86.

17. Mutsaerts MA, van Oers AM, Groen H, Burggraaff JM, Kuchenbecker WK, Perquin DA, et al. Randomized Trial of a Lifestyle Program in Obese Infertile Women. N Engl J Med. 2016:374:1942-53.

18. Fayh AP, Lopes AL, da Silva AM, Reischak-Oliveira A, Friedman R. Effects of $5 \%$ weight loss through diet or diet plus exercise on cardiovascular parameters of obese: a randomized clinical trial. Eur J Nutr. 2013;52:1443-50.

19. Ryan DH, Yockey SR. Weight loss and improvement in comorbidity: differences at 5\%, 10\%, 15\%, and over. Curr Obes Rep. 2017:6:187-94.

20. Williamson DA, Bray GA, Ryan DH. Is $5 \%$ weight loss a satisfactory criterion to define clinically significant weight loss? Obesity (Silver Spring). 2015;23: 2319-20.

21. Sheiner E, Balaban E, Dreiher J, Levi I, Levy A. Pregnancy outcome in patients following different types of bariatric surgeries. Obes Surg. 2009;19: 1286-92.

22. González I, Rubio MA, Cordido F, Bretón I, Morales MJ, Vilarrasa N, et al. Maternal and perinatal outcomes after bariatric surgery: a Spanish multicenter study. Obes Surg. 2015;25:436-42.
23. Santulli P, Mandelbrot L, Facchiano E, Dussaux C, Ceccaldi PF, Ledoux S, et al. Obstetrical and neonatal outcomes of pregnancies following gastric bypass surgery: a retrospective cohort study in a French referral centre. Obes Surg. 2010;20:1501-8.

24. Bebber FE, Rizzolli J, Casagrande DS, Rodrigues MT, Padoin AV, Mottin CC, et al. Pregnancy after bariatric surgery: 39 pregnancies follow-up in a multidisciplinary team. Obes Surg. 2011;21:1546-51.

25. Aricha-Tamir B, Weintraub AY, Levi I, Sheiner E. Downsizing pregnancy complications: a study of paired pregnancy outcomes before and after bariatric surgery. Surg Obes Relat Dis. 2012;8:434-9.

26. Johansson K, Cnattingius S, Näslund I, Roos N, Trolle Lagerros Y, Granath F, et al. Outcomes of pregnancy after bariatric surgery. N Engl J Med. 2015; 372:814-24

27. Catalano PM, Mele L, Landon MB, Ramin SM, Reddy UM, Casey B, et al. Inadequate weight gain in overweight and obese pregnant women: what is the effect on fetal growth? Am J Obstet Gynecol. 2014;211:137.e131-7.

28. Kort JD, Winget $\mathrm{C}, \mathrm{Kim} \mathrm{SH}$, Lathi RB. A retrospective cohort study to evaluate the impact of meaningful weight loss on fertility outcomes in an overweight population with infertility. Fertil Steril. 2014;101:1400-3.

29. Legro RS, Dodson WC, Kris-Etherton PM, Kunselman AR, Stetter CM, Williams $\mathrm{NI}$, et al. Randomized controlled trial of preconception interventions in infertile women with polycystic ovary syndrome. J Clin Endocrinol Metab. 2015;100:4048-58

30. Yang Q, Wang F. Successful pregnancy after improving insulin resistance with the glucagon-like peptide-1 analogue in a woman with polycystic ovary syndrome: a case report and review of the literature. Gynecol Obstet Investig. 2016;81:477-80.

31. Glastras SJ, Chen H, McGrath RT, Zaky AA, Gill AJ, Pollock CA, et al. Effect of GLP-1 receptor activation on offspring kidney health in a rat model of maternal obesity. Sci Rep. 2016;6:23525.

32. Nikolic D, Al-Rasadi K, Al Busaidi N, Al-Waili K, Banerjee Y, Al-Hashmi K, et al. Incretins, pregnancy, and gestational diabetes. Curr Pharm Biotechnol. 2016; 17:597-602.

33. Delbridge E, Proietto J. State of the science: VLED (Very Low Energy Diet) for obesity. Asia Pac J Clin Nutr. 2006;15(Suppl):49-54.

34. Purcell $K$, Sumithran $P$, Prendergast LA, Bouniu CJ, Delbridge E, Proietto J. The effect of rate of weight loss on long-term weight management: a randomised controlled trial. Lancet Diabetes Endocrinol. 2014;2:954-62.

35. McGrice M, Porter J. The effect of low carbohydrate diets on fertility hormones and outcomes in overweight and obese women: a systematic review. Nutrients. 2017;9:E204.

36. Sim KA, Partridge SR, Sainsbury A. Does weight loss in overweight or obese women improve fertility treatment outcomes? A systematic review. Obes Rev. 2014;15:839-50.

37. Grieger JA, Grzeskowiak LE, Clifton VL. Preconception dietary patterns in human pregnancies are associated with preterm delivery. J Nutr. 2014;144:1075-80.

38. Sussman D, van Eede M, Wong MD, Adamson SL, Henkelman M. Effects of a ketogenic diet during pregnancy on embryonic growth in the mouse. BMC Pregnancy Childbirth. 2013;13:109.

39. Niemeijer MN, Grooten IJ, Vos N, Bais JM, van der Post JA, Mol BW, et al. Diagnostic markers for hyperemesis gravidarum: a systematic review and metaanalysis. Am J Obstet Gynecol. 2014;211:150.e151-15.

40. Kurepa D, Pramanik AK, Kakkilaya V, Caldito G, Groome $\amalg$, Bocchini JA, et al. Elevated acetoacetate and monocyte chemotactic protein-1 levels in cord blood of infants of diabetic mothers. Neonatology. 2012;102:163-8.

41. Rudolf MC, Sherwin RS. Maternal ketosis and its effects on the fetus. Clin Endocrinol Metab. 1983;12:413-28.

42. Sim KA, Dezarnaulds GM, Denyer GS, Skilton MR, Caterson ID. Weight loss improves reproductive outcomes in obese women undergoing fertility treatment: a randomized controlled trial. Clin Obes. 2014:4:61-8.

43. Tsagareli $V$, Noakes $M$, Norman RJ. Effect of a very-low-calorie diet on in vitro fertilization outcomes. Fertil Steril. 2006:86:227-9.

44. Ahima RS, Flier JS. Adipose tissue as an endocrine organ. Trends Endocrinol Metab. 2000:11:327-32.

45. Catalano PM, Hauguel-De Mouzon S. Is it time to revisit the Pedersen hypothesis in the face of the obesity epidemic? Am J Obstet Gynecol. 2011; 204:479-87

46. Catalano PM, Huston L, Amini SB, Kalhan SC. Longitudinal changes in glucose metabolism during pregnancy in obese women with normal glucose tolerance and gestational diabetes mellitus. Am J Obstet Gynecol. 1999;180:903-16. 
47. Barbour LA, McCurdy CE, Hernandez TL, Kirwan JP, Catalano PM, Friedman JE. Cellular mechanisms for insulin resistance in normal pregnancy and gestational diabetes. Diabetes Care. 2007;30(Suppl 2):S112-9.

48. Metzger BE, Lowe LP, Dyer AR, Trimble ER, Chaovarindr U, Coustan DR, et al. Hyperglycemia and adverse pregnancy outcomes. N Engl J Med. 2008;358: 1991-2002.

49. Catalano PM, Mclntyre HD, Cruickshank JK, McCance DR, Dyer AR, Metzger $\mathrm{BE}$, et al. The hyperglycemia and adverse pregnancy outcome study: associations of GDM and obesity with pregnancy outcomes. Diabetes Care. 2012;35:780-6.

50. Sumithran P, Prendergast LA, Delbridge E, Purcell K, Shulkes A, Kriketos A, et al. Long-term persistence of hormonal adaptations to weight loss. N Engl J Med. 2011;365:1597-604.

51. Anderson JW, Konz EC, Frederich RC, Wood CL. Long-term weight-loss maintenance: a meta-analysis of US studies. Am J Clin Nutr. 2001;74:579-84.

52. Sumithran P, Proietto J. Maintaining weight loss: an ongoing challenge. Curr Obes Rep. 2016;5:383-5.

53. Ma RC, Schmidt MI, Tam WH, McIntyre HD, Catalano PM. Clinical management of pregnancy in the obese mother: before conception, during pregnancy, and post partum. Lancet Diabetes Endocrinol. 2016:4:1037-49.

54. Mottola MF. Physical activity and maternal obesity: cardiovascular adaptations, exercise recommendations, and pregnancy outcomes. Nutr Rev. 2013;71(Suppl 1):S31-6.

55. Galtier-Dereure F, Montpeyroux F, Boulot P, Bringer J, Jaffiol C. Weight excess before pregnancy: complications and cost. Int J Obes Relat Metab Disord. 1995;19:443-8

56. Skouteris H, Huang T, Millar L, Kuhlberg J, Dodd J, Callaway L, et al. A systems approach to reducing maternal obesity: The Health in Preconception, Pregnancy and Postbirth (HIPPP) Collaborative. Aust N Z J Obstet Gynaecol. 2015;55:397-400.

57. Group HSCR. Hyperglycemia and Adverse Pregnancy Outcome (HAPO) Study: associations with neonatal anthropometrics. Diabetes. 2009;58:453-9.

58. Xia C, Liu O, Wang L, Xu G. Trueness assessment for serum glucose measurement using commercial systems through the preparation of commutable reference materials. Ann Lab Med. 2012;32:243-9.

59. Kannieappan LM, Deussen AR, Grivell RM, Yelland L, Dodd JM. Developing a tool for obtaining maternal skinfold thickness measurements and assessing inter-observer variability among pregnant women who are overweight and obese. BMC Pregnancy Childbirth. 2013;13:42.

60. Catalano PM, Thomas AJ, Avallone DA, Amini SB. Anthropometric estimation of neonatal body composition. Am J Obstet Gynecol. 1995;173:1176-81.

61. Rothberg A, Lanham M, Randolph J, Fowler C, Miller N, Smith Y. Feasibility of a brief, intensive weight loss intervention to improve reproductive outcomes in obese, subfertile women: a pilot study. Fertil Steril. 2016;106: 1212-20.

62. Galtier-Dereure F, Boegner C, Bringer J. Obesity and pregnancy: complications and cost. Am J Clin Nutr. 2000;71:1242S-8S.

63. Morgan KL, Rahman MA, Macey S, Atkinson MD, Hill RA, Khanom A, et al. Obesity in pregnancy: a retrospective prevalence-based study on health service utilisation and costs on the NHS. BMJ Open. 2014;4:e003983.

64. Bays $\mathrm{H}$, Scinta W. Adiposopathy and epigenetics: an introduction to obesity as a transgenerational disease. Curr Med Res Opin. 2015;31:2059-69.

65. Vickers $\mathrm{MH}$. Developmental programming and transgenerational transmission of obesity. Ann Nutr Metab. 2014;64(Suppl 1):26-34.

66. Lassance L, Haghiac M, Leahy P, Basu S, Minium J, Zhou J, et al. Identification of early transcriptome signatures in placenta exposed to insulin and obesity. Am J Obstet Gynecol. 2015;212:647.e641-11.

67. Moran L, Tsagareli V, Norman R, Noakes M. Diet and IVF pilot study: shortterm weight loss improves pregnancy rates in overweight/obese women undertaking IVF. Aust N Z J Obstet Gynaecol. 2011;51:455-9.

\section{Submit your next manuscript to BioMed Central and we will help you at every step:}

- We accept pre-submission inquiries

- Our selector tool helps you to find the most relevant journal

- We provide round the clock customer support

- Convenient online submission

- Thorough peer review

- Inclusion in PubMed and all major indexing services

- Maximum visibility for your research

Submit your manuscript at www.biomedcentral.com/submit
C Biomed Central 